\title{
Diagnostic utility of flumazenil in coma with suspected poisoning: a double blind, randomised controlled study
}

\author{
Jonas Höjer, Svante Baehrendtz, Georg Matell, Lars L Gustafsson
}

Abstract

Objective-To assess the diagnostic value and safety of the benzodiazepine antagonist flumazenil in patients with coma of unclear origin with suspected poisoning.

Design-Double blind, placebo controlled, randomised study.

Setting-Intensive care unit at a major teaching hospital.

Patients-105 Unconscious adults admitted consecutively with suspected drug overdosage during 18 months from a total of 362 cases of poisoning. Exclusion criteria were pregnancy, epilepsy, obvious poisoning with drugs identified unequivocally from information from relatives or others as other than benzodiazepines, and coma score $>10$ on a scale graded from 4 to 20 . Patients were allocated randomly to receive flumazenil (21 men and 32 women) or placebo ( 25 men and 27 women).

Interventions - Intravenous injection of flumazenil $(10 \mathrm{ml}, 0.1 \mathrm{mg} / \mathrm{ml})$ or placebo $(10 \mathrm{ml}$ vehicle alone) given double blind over three minutes.

Main outcome measures-Serum and urine concentrations of benzodiazepines, antidepressants, and several other agents; blood gas tensions; standardised evaluation on admission and five minutes after the injection by means of coma scale score and urgent diagnostic or therapeutic interventions indicated according to the history and clinical examination; standardised interview after the injection to try to ascertain further information; and adverse reactions.

Results-Benzodiazepines were found in the serum in $\mathbf{3 6}$ of the 53 patients in the flumazenil group and in 37 of the 52 who received placebo. The average coma scale score increased significantly after injection in the flumazenil group (6.4 $v 12 \cdot 1$, $\mathbf{p}<\mathbf{0 . 0 0 1}$ ) but not in the placebo group. In the flumazenil group several interventions were rendered unnecessary by the injection: gastric lavage and urinary catheterisation (19 patients each), intubation (21), artificial ventilation and computed tomography of the brain (three patients each), blood culture and lumbar puncture (one patient each), and electroencephalography (two). In the placebo group the indications for these procedures did not change in any patient after injection. The $95 \%$ confidence interval for the difference in reduction of the frequency of indications for gastric lavage after injection between the two groups was $21 \%$ to $51 \%$, that for intubation $25 \%$ to $55 \%$, and that for urinary catheterisation $21 \%$ to $51 \%$. In the flumazenil group 21 patients gave valuable information on their drug ingestion within 10 minutes after injection compared with only one in the placebo group $(\mathbf{p}<0.001)$. Nine adverse reactions were recorded in the flumazenil group, eight of which were graded as mild and one severe. The safety of the antagonist was acceptable, even though $60 \%$ of the patients in the flumazenil group had multiple drug poisoning including benzodiazepine. No epileptic seizures or arrhythmias were recorded.

Conclusion-Flumazenil is a valuable and safe differential diagnostic tool in unclear cases of multiple drug poisoning.

\section{Introduction}

Patients with coma of unknown aetiology are commonly admitted to the emergency room. They constitute a high risk group ${ }^{12}$ requiring instant management and often extensive diagnostic procedures, such as lumbar puncture, blood cultures, electroencephalography, or computed tomography of the brain. ${ }^{23}$ Unconsciousness has various possible causes including severe infection, respiratory failure, metabolic disorders, cerebrovascular incidents, and poisoning, which is the most common. ${ }^{24}$ In cases of self induced poisoning the drugs ingested are commonly a mixture of several compounds, and their identity is often unknown. ${ }^{56}$ Standard treatment including intubation, gastric lavage, and giving activated charcoal is therefore often indicated. ${ }^{367}$

The benzodiazepines are the most commonly used drugs in self poisoning ${ }^{3}$; they have been reported to be involved in about half of all drug poisonings in several countries. ${ }^{68}$ The introduction of flumazenil, a selective benzodiazepine antagonist, ${ }^{9}$ has opened new possibilities for emergency management in such cases. Many have suggested that flumazenil should be used as a differential diagnostic tool in suspected poisoning of unclear cause ${ }^{10}{ }^{11}$ and case reports of this application have recently been described. ${ }^{12}{ }^{13}$ Others have urged extreme caution in the use of flumazenil in multiple drug overdosage including benzodiazepines. ${ }^{14}$ is However, no controlled study for evaluation of its use in this way has been reported.

The aim of this investigation was to appraise the diagnostic value and safety of flumazenil in patients with coma of unclear aetiology in which benzodiazepine overdosage could not be ruled out as a main or a contributory cause of decreased consciousness.

\section{Patients and methods}

We investigated 105 patients (mean age 42 (range 1783)) admitted consecutively to the medical intensive care unit of the Southern Hospital with suspected poisoning. A criterion for enrolment was unconsciousness defined as less than 11 points on a modified Glasgow coma scale ${ }^{16}$ on admission. The scale was graded from 4 to 20 (table I). Patients in whom benzodiazepine poisoning could be ruled out from information from relatives or others were excluded. Further exclusion criteria were pregnancy and epilepsy. The study was performed over 18 months, during which a total of 362 patients with poisoning were treated at the unit. Most of them were excluded from the study because their level of consciousness on admission was too high; the 105 patients included were randomly allocated to a flumazenil group ( 21 men and 32 women) or a placebo group ( 25 men and 27 women).

The patients were enrolled into the study, evaluated, and treated by the physician on duty at the unit. Samples of blood and urine for toxicological examinations were taken on admission. Samples of arterial 
blood for analysis of blood gas tensions were taken on admission, before any supplementary oxygen was given. Patients were monitored continously throughout the study by electrocardiography, and a conventional 12 lead electrocardiogram was recorded in all patients. Shortly after admission each patient was evaluated in terms of the acute interventions indicated from his or her history and clinical examination. The physician was instructed to follow the standard routines, including intubation for gastric lavage and giving charcoal in comatose patients with suspected serious self poisoning, artificial ventilation in patients with severe respiratory depression, and urinary catheterisation in patients with urinary retention if urine analysis was needed urgently. The evaluation was performed according to a specially designed protocol including the interventions listed in table II. The level of consciousness was assessed according to the modified Glasgow coma scale.

Immediately after the scoring procedure and baseline evaluation an intravenous injection of active drug $(10 \mathrm{ml}$ flumazenil $0 \cdot 1 \mathrm{mg} / \mathrm{ml})$ or placebo $(10 \mathrm{ml}$ vehicle alone) was given double blind over three minutes. Five minutes after the end of the injection the indications for interventions were again evaluated and the coma score was assessed. In addition, a standardised interview was conducted with the patient, the result of which was classified into three categories: $(a)$ no comprehensible verbal response, $(b)$ able to speak but gave no additional information about the drugs ingested, and $(c)$ gave valuable information on drug intake. Finally, any adverse reactions to flumazenil were recorded. These were graded as severe, moderate, or mild. Ten minutes after the injection a further blood sample for blood gas analysis was taken, and 15 minutes after the injection the coma score was again assessed, completing the study protocol.

For ethical reasons the code was disclosed after completion of each individual protocol, so that patients who had received placebo could be given flumazenil in an open design and separately from the study protocol if indicated. After completion of the protocol in each patient in the flumazenil group the interventions that were considered to be indicated at the evaluation after injection were performed. The corresponding interventions indicated in the patients in the placebo group were also carried out if the flumazenil given after the study did not dramatically alter the clinical picture. The study was approved by the local ethics committee.

\section{Analytical methods}

In all patients the serum concentrations of benzodiazepine derivatives were assayed in duplicate by gas chromatography with the "electron capture detector" technique. ${ }^{1819}$ The serum concentrations of ethanol, methanol, and paracetamol were also determined in all patients with standard procedures. A qualitative screening method for urinary amine was used to detect

TABLE II - Evaluation of indications for diagnostic or therapeutic interventions immediately before and five minutes after double blind injection of flumazenil or placebo

\begin{tabular}{|c|c|c|c|c|c|}
\hline \multirow[b]{3}{*}{ Interventions studied } & \multicolumn{4}{|c|}{$\begin{array}{l}\text { No }(\%) \text { of patients with urgent indication } \\
\text { for intervention }\end{array}$} & \multirow{3}{*}{$\begin{array}{l}\text { \% Difference ( } 95 \% \text { confidence interval) in } \\
\text { reduction of frequency of indications for } \\
\text { interventions after injection between groups }\end{array}$} \\
\hline & \multicolumn{2}{|c|}{$\begin{array}{l}\text { Flumazenil group } \\
\qquad(\mathrm{n}=53)\end{array}$} & \multicolumn{2}{|c|}{$\begin{array}{l}\text { Placebogroup } \\
\qquad(\mathrm{n}=52)\end{array}$} & \\
\hline & $\begin{array}{c}\text { Before } \\
\text { injection }\end{array}$ & $\begin{array}{c}\text { After } \\
\text { injection }\end{array}$ & $\begin{array}{c}\text { Before } \\
\text { injection }\end{array}$ & $\begin{array}{c}\text { After } \\
\text { injection }\end{array}$ & \\
\hline Gastric lavage & $40(76)$ & $21(40)$ & $31(60)$ & $31(60)$ & $36(21$ to 51$)$ \\
\hline Intubation & $40(76)$ & $19(36)$ & $33(63)$ & $33(63)$ & $40(25$ to 55$)$ \\
\hline Urinary catheterisation & $39(74)$ & $20(38)$ & $37(71)$ & $37(71)$ & $36(21$ to 51$)$ \\
\hline Artificial ventilation & $7(13)$ & $4(8)$ & $10(19)$ & $10(19)$ & $6(0$ to 12$)$ \\
\hline Computed tomography of & & & & & \\
\hline the & $6(11)$ & $3(6)$ & $5(10)$ & $5(10)$ & $6(0$ to 12$)$ \\
\hline Electroencephalography & $3(6)$ & $1(2)$ & $1(2)$ & $1(2)$ & 4 Not tested \\
\hline Analysis of spinal fluid & $2(4)$ & $1(2)$ & $3(6)$ & $3(6)$ & 2 Not tested \\
\hline Blood cultures & $1(2)$ & 0 & $5(10)$ & $5(10)$ & 2 Not tested \\
\hline
\end{tabular}

phenothiazines. ${ }^{20}$ This method gives false positive results for antihistamines and for high concentrations of antidepressants. In patients with suspected intake of polycyclic antidepressant drugs the serum concentrations of these drugs were determined in duplicate by high performance liquid chromatography. ${ }^{21}$ Other suspected agents were also assayed in the serum or urine, or both, in several patients.

\section{Statistical methods}

We calculated $95 \%$ confidence intervals for the difference between the two groups in the reduction of the frequency of indications for interventions after injection. $\chi^{2}$ tests were used to analyse the results of the standardised interview, and Student's $t$ test for paired or unpaired values was used for the coma scores and blood gas tensions.

\section{Results}

Among the 105 unconscious patients, two had negative results on toxicological examination and their condition was not diagnosed as self poisoning. One was a man with an intracerebral haemorrhage and the other was a woman with chronic obstructive pulmonary disease and acute respiratory failure. In addition, one patient had a subarachnoid haemorrhage after an overdose of amphetamine and another had combined poisoning with benzodiazepines and propiomazine and streptococcal septicaemia.

\section{Toxicological examinations}

Thirty six patients in the flumazenil group and 37 in the placebo group were found to have taken overdoses of benzodiazepines. Ethanol was present in the serum in 28 patients in the flumazenil group (mean $52 \mathrm{mmol} / \mathrm{l}$ $(240 \mathrm{mg} / 100 \mathrm{ml})$ ) and in 27 in the placebo group (mean $63 \mathrm{mmol} / \mathrm{l}(290 \mathrm{mg} / 100 \mathrm{ml}))$. Other commonly detected drugs were phenothiazines (20 patients in the flumazenil group and 12 in the placebo group) and polycyclic antidepressants (eight and five patients respectively). Some serum samples were also positive for hexapropymate (four patients), barbiturate and paracetamol (three patients each), dextropropoxyphene and meprobamate (two patients each), carbamazepine, salicylate, chloral hydrate, diphenhydramine, amphetamine, and methaqualone (one patient each).

\section{Interventions}

In 27 of the 53 patients in the flumazenil group the indication for at least one of the interventions studied was rendered unnecessary by the injection of drug. The total numbers of these eliminated interventions were: gastric lavage (19 patients), intubation (21), urinary catheterisation (19), artificial ventilation (three), computed tomography of the brain (three), electroencephalography (two), lumbar puncture (one), and blood culture (one) (table II); nor were these interventions performed later during the patients' stay at the hospital.

\section{Interview after injection}

None of the patients gave a comprehensible verbal response on admission. In the flumazenil group 21 of the 53 patients were able to speak and give valuable information on ingestion of drugs within 10 minutes after the injection, and the corresponding number in the placebo group was one of 52 patients $(p<0.001)$ (table III).

\section{Blood gas tensions}

In the flumazenil group the mean arterial carbon dioxide tension on admission was $6.0 \mathrm{kPa}$ and the mean arterial oxygen tension $10.5 \mathrm{kPa}$. Ten minutes after the flumazenil injection the mean arterial carbon dioxide 
TABLE III - Results of interview conducted five to 10 minutes after the end of the injection of flumazenil or placebo (figures are numbers of patients)

\begin{tabular}{lcc}
\hline Patient's response & $\begin{array}{c}\text { Flumazenil group } \\
(\mathrm{n}=53)\end{array}$ & $\begin{array}{c}\text { Placebo group } \\
(\mathrm{n}=52)\end{array}$ \\
\hline $\begin{array}{l}\text { Able to speak and gave } \\
\text { valuable information on } \\
\text { drug ingestion }\end{array}$ & $21^{\star}$ & 1 \\
$\begin{array}{l}\text { Able to speak but gave no } \\
\text { new information }\end{array}$ & 6 & 2 \\
$\begin{array}{l}\text { No comprehensible verbal } \\
\text { response }\end{array}$ & 26 & 49 \\
\hline * $p<0 \cdot 001$ Compared with number of patients in placebo group in the \\
corresponding category.
\end{tabular}

tension had decreased significantly to $5 \cdot 6 \mathrm{kPa}(\mathrm{p}<0 \cdot 01)$ and oxygen tension had increased to $11 \cdot 3 \mathrm{kPa}$ $(\mathrm{p}<0.01)$. In the placebo group the blood gas tensions on admission were not significantly different from those in the flumazenil group, and they did not change after the injection of placebo. In eight of the 105 patients one or both of the arterial blood samples were never measured, and in another 18 patients supplementary oxygen had been given before the second sample was taken. The mean values for blood gas tensions are therefore based on samples from 79 patients (44 in the flumazenil group and 35 in the placebo group).

\section{Adverse reactions}

Nine episodes of adverse reactions were recorded in the flumazenil group; eight were graded as mild and were observed five to 15 minutes after the patient regained consciousness. They were reported as agitation (three patients), a depressive mood (three), nausea and vomiting (one), and shivering (one). One adverse reaction, graded as severe and reported as a sudden fall in blood pressure, occurred in a 28 year old woman in deep coma after combined poisoning with benzodiazepines and maprotiline. Two minutes after the injection of flumazenil her coma score increased from 4 to 10 and at the same time her systolic blood pressure fell from $100 \mathrm{~mm} \mathrm{Hg}$ to $60 \mathrm{~mm} \mathrm{Hg}$. No arrhythmia was noted. She was immediately intubated for gastric lavage and given fluid intravenously, and after about 15 minutes her haemodynamic values were normal. In the placebo group two adverse reactions were recorded after the injection and were reported as mild shivering and moderate pain at the injection site. Ten patients in the study in whom laboratory examinations confirmed overdosage with a combination of benzodiazepines and polycyclic antidepressants were given flumazenil. Eight of them had high serum concentrations of antidepressants ${ }^{2223}$ and three showed transient electrocardiographic signs of cardiac affection on admission; only one, however, reacted unfavourably to the antidote (table IV).

\section{Level of consciousness}

The average coma scale score on admission in the flumazenil group was 6.4 ; five minutes after the injection it had increased significantly to $12 \cdot 1$ $(p<0.001)$. In the placebo group the average coma score of 6.6 on admission was not significantly different from that in the flumazenil group, and it did not change after the injection of placebo. The mean time spent in the intensive care unit by the 105 patients was 32 hours (range 4-164). All patients except two were in a stable somatic condition and fully awake when discharged. One patient with an intracerebral haemorrhage was still in a coma on transfer to a neurosurgical department, and one with a subarachnoid haemorrhage died in the unit after 32 hours' mechanical ventilation.

\section{Discussion}

This investigation shows the diagnostic utility of flumazenil in coma with suspected poisoning. The fact that gastric lavage, intubation, and urinary catheterisation may be avoided in several cases after giving flumazenil greatly benefits patients as these procedures are not without complications. ${ }^{3}$ This and the finding that other interventions, such as artificial ventilation and computed tomography of the brain, were also rendered unnecessary by flumazenil in some patients are important in the optimal utilisation of hospital resources. Furthermore, the fact that $40 \%$ (21) of the patients in the flumazenil group were able to give important information about their ingested drugs shortly after injection despite the fact that only four of the 53 patients in this group had taken benzodiazepines alone emphasises the value of the antagonist as a differential diagnostic tool.

TABLE IV-Summary of clinical and toxicological data on 10 patients with combined poisoning with benzodiazepines and polycyclic antidepressants receiving $1 \cdot 0$ mg intravenous flumazenil

\begin{tabular}{|c|c|c|c|c|c|}
\hline Patient No & $\begin{array}{l}\text { Serum } \\
\text { benzodiazepines } \\
(\mathrm{nmol} / \mathrm{l})\end{array}$ & $\begin{array}{l}\text { Serum } \\
\text { antidepressants } \\
(\mathrm{nmol} / \mathrm{l})\end{array}$ & $\begin{array}{c}\text { Diagnostic } \\
\text { electrocardiogram }\end{array}$ & $\begin{array}{l}\text { Adverse effect } \\
\text { with flumazenil }\end{array}$ & $\begin{array}{l}\text { Treatment after } \\
\text { flumazenil }\end{array}$ \\
\hline 1 & $\begin{array}{l}\text { Diazepam }(4400) \\
\text { Desmethyldiazepam }(12000) \\
\text { Nitrazepam }(46000) \\
\text { Flunitrazepam }(200)\end{array}$ & $\begin{array}{l}\text { Amitriptyline (2300) } \\
\text { Nortriptyline ( } 300)\end{array}$ & Normal & None* & $\begin{array}{l}\text { Intubation, gastric lavage, artificial } \\
\text { ventilation }\end{array}$ \\
\hline 2 & $\begin{array}{l}\text { Diazepam }(600) \\
\text { Desmethyldiazepam }(4600)\end{array}$ & $\begin{array}{l}\text { Amitriptyline ( } 2700) \\
\text { Nortriptyline }(400)\end{array}$ & Normal & None & $\begin{array}{l}\text { Intubation, gastric lavage, artificial } \\
\text { ventilation }\end{array}$ \\
\hline 3 & Oxazepam (39000) & $\begin{array}{l}\text { Clomipramine (600) } \\
\text { Desmethylclomipramine (400) }\end{array}$ & Normal & None & Intubation, gastric lavage \\
\hline 4 & $\begin{array}{l}\text { Lorazepam (positive) } \\
\text { Alprazolam (positive) }\end{array}$ & Maprotiline (1900) & Wide QRS complex & Acute fall in blood pressure & $\begin{array}{l}\text { Intubation, gastric lavage, extra } \\
\text { fluid treatment }\end{array}$ \\
\hline 5 & $\begin{array}{l}\text { Diazepam }(3100) \\
\text { Nitrazepam }(900) \\
\text { Oxazepam }(10200)\end{array}$ & $\begin{array}{l}\text { Maprotiline (1100) } \\
\text { Clomipramine (300) } \\
\text { Desmethylclomipramine (100) }\end{array}$ & Normal & None $^{\star}$ & $\begin{array}{l}\text { Intubation, gastric lavage, artificial } \\
\text { ventilation }\end{array}$ \\
\hline 6 & $\begin{array}{l}\text { Diazepam (1900) } \\
\text { Desmethyldiazepam (2400) } \\
\text { Flunitrazepam }(40)\end{array}$ & $\begin{array}{l}\text { Amitriptyline (1700) } \\
\text { Nortriptyline ( } 800)\end{array}$ & Sinus tachycardia & None & Intubation, gastric lavage \\
\hline 7 & Nitrazepam (4000) & $\begin{array}{l}\text { Amitriptyline (1400) } \\
\text { Nortriptyline (200) }\end{array}$ & Normal & None & $\begin{array}{l}\text { Intubation, gastric lavage, artificial } \\
\text { ventilation }\end{array}$ \\
\hline 8 & $\begin{array}{l}\text { Oxazepam }(15000) \\
\text { Flunitrazepam }(70)\end{array}$ & $\begin{array}{l}\text { Amitriptyline ( } 3200) \\
\text { Nortriptyline }(900)\end{array}$ & Wide QRS complex & None & Intubation, gastric lavage \\
\hline 9 & Nitrazepam (1000) & Clomipramine (400) & Normal & None ${ }^{\star}$ & Observation \\
\hline 10 & $\begin{array}{l}\text { Diazepam (400) } \\
\text { Desmethyldiazepam (200) } \\
\text { Nitrazepam (3100) }\end{array}$ & $\begin{array}{l}\text { Amitriptyline (2500) } \\
\text { Nortriptyline (200) }\end{array}$ & Wide QRS complex & None & Intubation, gastric lavage \\
\hline
\end{tabular}

Therapeutic concentration of the sum of amitriptyline and nortriptyline $=400-800 \mathrm{nmol} / 1:$ and of maprotiline $=650-950 \mathrm{nmol} / / 2:$ Steady state concentrations with therapeutic doses of

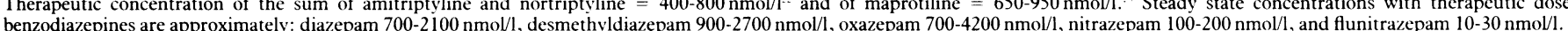
•enzodiazepines are approximately: diazepam $700-2100 \mathrm{nmol} / \mathrm{l}$, desmethy/dia 
Among the many patients who reacted favourably to the antidote was a 58 year old woman with chronic obstructive pulmonary disease who was admitted with deep coma of unknown aetiology. She was breathing superficially at a frequency of 42 breaths/minute and had an arterial carbon dioxide tension of $12.9 \mathrm{kPa}$. Five minutes after the blind injection of flumazenil, which rendered planned intubation, gastric lavage, artificial ventilation, and computed tomography unnecessary, she was almost completely awake and admitted overdosage with benzodiazepines. Ten minutes after the injection her breathing frequency was 18 breaths/ minute and her arterial carbon dioxide tension was $8 \cdot 7 \mathrm{kPa}$. Her consciousness decreased somewhat during the next hours, but none of the interventions studied were needed. The favourable effect of flumazenil on gas exchange, in this patient as in the full study, supports previous observations of the ability of the drug to reverse respiratory depression induced by benzodiazepines. ${ }^{24}$

The safety of flumazenil in this study was acceptable, which is noteworthy, considering that 32 of the 53 patients in the flumazenil group had mixed drug poisoning with involvement of benzodiazepines. Only one severe adverse reaction was recorded, that of a sudden fall in blood pressure that occurred in a patient poisoned with a combination of benzodiazepines and a polycyclic antidepressant (case 4, table IV). The mechanism underlying this hypotensive event, which was probably precipitated by flumazenil, is not clear. Cases have been reported of patients with combined overdosage with benzodiazepines and some epileptogenic or cardiotoxic drug in whom flumazenil induced convulsions ${ }^{14}$ or ventricular arrhythmias. ${ }^{15}$ Epileptic seizures are a recognised hazard in the use of flumazenil in patients with epilepsy regularly treated with benzodiazepines. ${ }^{25}$ The suggested explanation for the possible provocation of rhythm disturbances by flumazenil in multiple drug poisoning is that the direct effect of a cardiotoxic compound on the heart may be accentuated by the reversal of the dampening effect of benzodiazepines on sympathetic nervous activity. ${ }^{15}$ The patient with an acute fall in blood pressure in this study, however, had no arrhythmia, which often is associated with hypotension in severe overdosage with antidepressants. ${ }^{26}$ Another conceivable cause of hypotension induced by antidepressant drugs is the quinidine-like direct depressive effect on the myocardium. Whether benzodiazepines in some way counteract this effect, however, is not known. The few cases reported of severe symptoms precipitated by flumazenil must not cloud its demonstrated and obvious clinical utility, particularly in unclear cases of multiple drug poisoning. Naturally, flumazenil must be used with caution in these patients. Epilepsy is a definite contraindication. A diagnostic electrocardiogram should be recorded before flumazenil is given, since a QRS duration of $0 \cdot 10 \mathrm{~s}$ or greater indicates serious overdosage with tricyclic antidepressants. ${ }^{27}$ In comatose patients with suspected drug poisoning and such electrocardiographic changes the measures required are immediate intubation, gastric lavage, activated charcoal, and sometimes controlled ventilation rather than a potentially risky and probably ineffective injection of flumazenil.

We conclude that flumazenil is a valuable and safe diagnostic tool in suspected poisoning of unclear origin. A normal electrocardiogram recorded before giving the antidote will imply a minimal risk of any adverse reactions in cases of combined intake of benzodiazepines and antidepressants.

1 Levy DE, Bates D, Caronna JJ, et al. Prognosis in nontraumatic coma. Ann Intern Med 1981;94:293-301.

2 Plum F, Posner JB. Approach to the unconscious patient. In: The diagnosis of supor and coma. 3rd ed. Philadelphia: FA Davis, 1980:345-64.

3 Höjer J, Baehrendtz S, Gustafsson L. Benzodiazepine poisoning. Experience of 702 admissions to an intensive care unit during a 14-year period. fournal of of 702 admissions to an intensive care

4 Rubenstein E. Intoxication by centrally acting agents. In: Rubenstein E, Federman DD, eds. Scientific American medicine. New York: Scientific American, 1989:2-13.

5 Hardwicke C, Holt L, James R, Smith AJ. Trends in self-poisoning with drugs in Newcastle, New South Wales, 1980-1982. Med f Aust 1986;144:453-4.

6 Leykin Y, Halpern P, Silbiger A, et al. Acute poisoning treated in the intensive care unit: a case series. Isrl F Med Sci 1989;25:98-102.

7 Proudfoot AT, Park J. Changing pattern of drugs used for self-poisoning. BMF 1978;i:90-3.

8 Willox DGA. Self poisoning. A review of patients seen in the Victoria Infirmary, Glasgow. Scott Med f 1985;30:220-4.

9 Hunkeler W, Möhler H, Pieri L, et al. Selective antagonists of benzodiazepines. Nature 1981;290:514-6.

10 Höjer J. Baehrendtz S. The effect of flumazenil (Ro 15-1788) in the management of self-induced benzodiazepine poisoning. A double blind controlled study. Acta Med Scand 1988:244:357-65.

11 Geller E, Niv D, Weinbrum A, Silbiger A, Halpern P, Sorkine P. The use of flumazenil in the treatment of 34 intoxicated patients. Resuscitation 1988 16(suppl):57-62.

12 Burkhart KK, Kulig KW. The diagnostic utility of flumazenil (a benzodiazepine antagonist) in coma of unknown etiology. Ann Emerg Med 1990;19:319-21.

13 Gijsenbergh FP, Pillen EJ, Delooz HH. Differential diagnostic value and influence on EEG of Anexate (flumazenil, Ro 15-1788) in benzodiazepineintoxication. A case report. Acta Anaesthesiol Belg 1989;40:127-9.

14 Burr W, Sandham P, Judd A. Death after flumazenil. BMF 1989;298:1713.

15 Short TG, Maling T, Galletly DC. Ventricular arrhythmia precipitated by flumazenil. BMF 1988;296:1070-1.

16 Teasdale G, Jennett B. Assessment of coma and impaired consciousness-a practical scale. Lancet 1974;ii:81-4.

17 Teasdale G, Murray G, Parker L, Jennett B. Adding up the Glasgow coma score. Acta Neurochir (Wien) 1979;28 (suppl):13-6.

18 Weinfeld RE, Posmonter HIV, Khoo KG, Pulsi CV Rapid determination of diazepam and nordiazepam in plasma by electron capture gas-liquid chemistry I Chromatoor 1977; 143:581-95.

19 de Silva A, Bekersky I, Puglisi C, Brooks M, Weinfeld RE. Determination of 1,4-benzodiazepines and -diazepin-2-ones in blood by electron-capture-gasliquid chromatography. Anal Chem 1976;48:10-9.

20 Salzman NP, Brodie BB. Physiological disposition and fate of chlorpromazin and a method for its estimation in biological material. $\mathcal{I}$ Pharmacol Exp The 1956;118:46-54.

21 Visser T, Oostelbos $M$, Toll P. Reliable routine method for the determination of antidepressant drugs in plasma by high-performance liquid chromatography. F Chromatogr 1984;309:81-93.

22 Van Brunt $\mathrm{N}$. The clinical utility of tricyclic antidepressant blood levels: review of the literature. Ther Drug Monit 1983:5:1-10.

23 Pinder RM, Brogden RN, Speight TM, Avery GS. Maprotiline: a review of its pharmacological properties and therapeutic efficacy in mental depressive pharmacological properties and
states. Drugs 1977;13:321-52.

24 Mora CT, Toriman M, White PF. Effects of diazepam and flumazenil on sedation and hypoxic ventilatory response. Anesth Analg 1989;68:473-8.

25 Bodenham AR. Death after flumazenil. BMF 1989;299:457.

26 Shannon M, Merola J, Lovejoy FH Jr. Hypotension in severe tricyclic hannon M, Merola J, Lovejoy FH Jr. Hypotension in
antidepressant overdose. Am f Emerg Med 1988;6:439-42.

27 Boehnert MT, Lovejoy FH Jr. Value of the QRS duration versus the serum drug level in predicting seizures and ventricular arrhythmias after an acute overdose of tricyclic antidepressants. $N$ Engl $\mathcal{F}$ Med 1985;313:474-9.

(Accepted 18 September 1990)

\section{ONE HUNDRED YEARS AGO}

It is stated that Sir George Grey intends shortly to ask the New Zealand legislature to adopt a measure "throwing open" the medical profession. We suppose this means the establishment of free trade in the practice of medicine, without the vexatious restrictions as to education, diplomas, and so forth at present imposed by a tyrannical law. Sir George appears to think that the great heart of the people may be trusted to distinguish quacks from true men among professors of the healing art with the same unerring instinct as it chooses its political guides; in any case he would probably argue that it is better a nation should be free than healthy. One clause in the Bill will provide that every prescription shall be written in English; of course spelling and grammar will be entirely optional. It is to be hoped, however, that the "openness" of practice may not extend to dosage.

(British Medical Fournal 1890;ii:511.) 